\title{
Enhancement of Bacterial Adhesion by Shear Forces: Characterization of the Haemagglutination Induced by Aeromonas salmonicida Strain 438
}

\author{
By D. E. BROOKS, ${ }^{1 *}$ AND T. J. TRUST ${ }^{2}$ \\ ${ }^{1}$ Departments of Pathology and Chemistry, University of British Columbia, Vancouver, B.C., \\ Canada V6T 1 W5 \\ ${ }^{2}$ Department of Biochemistry and Microbiology, University of Victoria, Victoria, B.C., \\ Canada V8W $2 Y 2$
}

(Received 16 March 1983; revised 4 July 1983)

\begin{abstract}
Application of a viscometric assay to the haemagglutination induced by Aeromonas salmonicida strain 438 showed that shear forces can enhance the strength of bacterial adhesion. The Dmannose/L-fucose-sensitive reaction proceeded in two phases, an initial phase in which the degree of aggregation remained constant during shearing and a second stage, induced by shear, in which agglutination was enhanced as shear was maintained. The results strongly paralleled those found in studies of concanavalin A-induced haemagglutination, providing good evidence that adhesion in this species took place via lectin-like molecules. Methyl- $\alpha$-D-mannoside, which strongly inhibits haemagglutination in this system, would not fully reverse the shear-dependent reaction. EGTA inhibited and reversed both phases, however. The effects of bacterial concentration, temperature, time of growth, $\mathrm{pH}$, and a spectrum of monosaccharide inhibitors were also studied. The results demonstrated that the shear-dependent reaction has a number of features which distinguish it from the initial stage of haemagglutination, implying differences in the underlying biochemical mechanisms involved.
\end{abstract}

\section{INTRODUCTION}

The ability of pathogenic bacteria to adhere to epithelia is believed to be an important determinant of virulence in many cases (Jones, 1977). On a number of these mucosal surfaces, the adherent bacteria are exposed to mechanical and fluid shearing forces imposed by mucus flow, cell movement, urine flow, blood flow and passage of gastrointestinal lumen contents. This surface shear has been regarded as a natural defence mechanism, based on the assumption that shearing will act to remove the bacterial cells from the animal cell surface. However, many bacterial species are able to successfully initiate infections on mucosal surfaces in spite of exposure to shearing, suggesting that bacteria may have adhesive mechanisms enabling them to cope with this feature of their environment. To date, very few in vitro studies on adhesion of bacteria to eucaryotic cells have considered the effects of shear and little information is available on this important determinant.

A number of techniques have been used to study bacterial adhesion; one general type of experiment which has been widely used is haemagglutination (Duguid \& Old, 1980). Simultaneous adhesion of bacteria to the surfaces of two or more erythrocytes can cause red cell aggregation via a bridging mechanism which may be detected visually on a slide or microtitre plate. Haemagglutination has been used to provide semi-quantitative information on the adhesive potential of a culture, while sugar inhibition of haemagglutination has allowed adhesive specificity to be demonstrated (Duguid \& Old, 1980).

Recently, we have developed an assay which allows the effect of shear forces on the adhesion of bacteria to erythrocytes to be specifically examined (Brooks \& Trust, 1980). The technique also provides quantitative information on the kinetics, reversibility and adhesive strength of the 


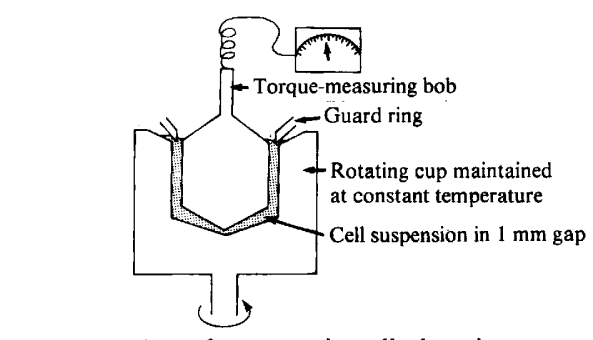

Cross-section of concentric cylinder viscometer

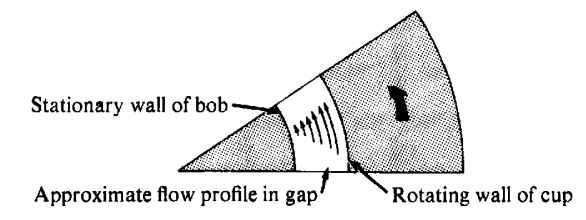

Transverse section showing flow profile

Fig. 1. Diagrammatic representation of a Couette viscometer.

attachment process. The assay is carried out in a variable shear rate viscometer and is an adaptation of our viscometric assay, recently applied to the study of lectin-induced aggregation (Greig \& Brooks, 1979; Greig \& Brooks, 1981). We have applied this assay to a model Dmannose/L-fucose-sensitive bacterial adhesion reaction.

\section{METHODS}

Bacteria and growth conditions. Aeromonas salmonicida strain 438 (T. P. T. Evelyn strain 76-30, Pacific Biological Station, Nanaimo, British Columbia, Canada) produces D-mannose/L-fucose-sensitive agglutination of human group $\mathrm{A}(+)$ erythrocytes (Trust et al., 1980). Stock cultures were maintained at $-80^{\circ} \mathrm{C}$ in $10 \%(\mathrm{v} / \mathrm{v})$ glycerolbrain heart infusion broth (Difco). For haemagglutination assays, cultures were grown as lawns on Trypticase Soy agar (BBL) at $25^{\circ} \mathrm{C}$ for various times. Stock suspensions of bacteria were suspended in glucose-free Hank's balanced salt solution (HBSS), pH 7.4, to a final numerical concentration of $2.3 \times 10^{11} \mathrm{ml}^{-1}$ for dilution into erythrocyte suspensions.

Viscometric haemagglutination assay. The assay was carried out by exposing a concentrated erythrocyte suspension to a constant shear rate in a rotational viscometer, the outer cup of which rotates at a set velocity and the inner bob of which (the measuring element) remains stationary. The cell suspension filled the $1 \mathrm{~mm}$ gap between the two surfaces and was sheared as the cup wall rotated. The torque transmitted by the fluid to the inner bob, proportional to the shear stress, was measured by the viscometer and was provided as a continuous output. The apparatus is schematically represented in Fig. 1. Because of the velocity gradient (numerically equal to the shear rate) across the gap, erythrocytes moving along streamlines radially displaced from one another are in relative motion. If the erythrocytes are aggregated due to the presence of adhering bacteria, the intercellular associations are of necessity broken down as flow occurs. A steady state in adhesive bond formation and breakdown is set up within a few seconds. The increased energy dissipation associated with disruption of the intercellular associations produces an increase in the apparent viscosity of the suspension, which in turn results in an increase in the shear stress measured (viscosity = shear stress/shear rate). A convenient index of the degree of cellular aggregation, and hence of the strength of bacterial adhesion, was provided therefore by the ratio, $R$, of apparent viscosities of aggregated and unaggregated suspensions at the same shear rate, cell concentration and suspending medium viscosity.

In a typical experiment fresh human $A(+)$ erythrocytes were washed three times in HBSS and suspended at a final haematocrit of $47 \%(\mathrm{v} / \mathrm{v})\left(5.2 \times 10^{9} \mathrm{cells} \mathrm{ml}^{-1}\right)$. An amount $(800 \mu \mathrm{l})$ of this suspension was placed in the cup of a Contraves LS-2 viscometer (Contraves AG, Schaffhauserstrasse 580, 8052 Zürich, Switzerland) utilizing a Couette measuring system fitted with a guard ring. Sample temperature was maintained, usually at $25.0 \pm 0 \cdot 1^{\circ} \mathrm{C}$, by means of a water circulator, and a constant shear rate, $49 \mathrm{~s}^{-1}$ unless otherwise indicated, was applied. The agglutination reaction was initiated by adding $100 \mu 1$ of the bacterial suspension (usually $2.3 \times 10^{10}$ cells) and mixing by slowly raising and lowering the bob of the viscometer several times while shearing was maintained. Shear stress output was recorded as a function of time. The control, which was subjected to the same procedure, consisted of an identical erythrocyte suspension diluted to the same extent as the experimental sample with the 


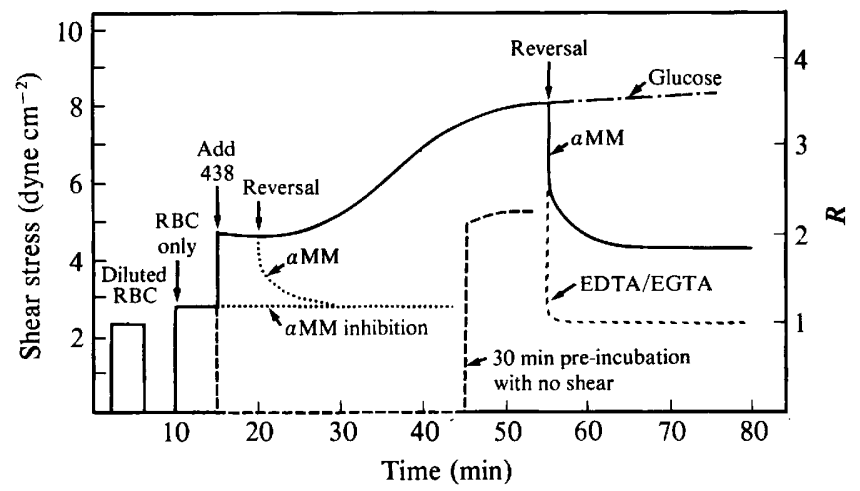

Fig. 2. Time dependence of the shear stress (left hand ordinate) and aggregation index, $R$, (right hand ordinate) observed for washed human erythrocytes suspended in HBSS to which $A$. salmonicida strain 438 bacteria grown for $42 \mathrm{~h}$ were added. $R$ is calculated as the ratio of shear stress recorded in the presence of bacteria to that recorded with a sample diluted equivalently with the same volume concentration of non-adherent bacteria (trace from 2 to $6 \mathrm{~min}$ on abscissa). When $\alpha$-methyl-D-mannoside ( $\alpha \mathrm{MM} ; 11 \mathrm{mM}$ final concentration) was added with the bacteria, the trace labelled $\alpha \mathrm{MM}$ inhibition was obtained. When $\alpha \mathrm{MM}$ was added $5 \mathrm{~min}$ or $40 \mathrm{~min}$ after the bacteria, the traces labelled $\alpha \mathrm{MM}$ at $20 \mathrm{~min}$ and $55 \mathrm{~min}$ on the abscissa resulted. When glucose (11 mM final concentration) or EDTA or EGTA ( $22 \mathrm{~mm}$ final concentration) were added $40 \mathrm{~min}$ after the bacteria, the traces so labelled at $55 \mathrm{~min}$ on the time axis were obtained. When, after adding the bacteria and mixing, shearing was stopped for $30 \mathrm{~min}$ then started after gentle mixing, the trace at $45 \mathrm{~min}$ on the abscissa was observed. The shear rate was $49 \mathrm{~s}^{-1}$, the temperature was $25.0 \pm 0.1{ }^{\circ} \mathrm{C}$, the haematocrit was $47 \%(\mathrm{v} / \mathrm{v})$, and the final bacterial concentration was $2.6 \times 10^{10} \mathrm{ml}^{-\frac{1}{1}}$.

bacterial suspending media. The $R$ value at any time was calculated as the ratio of the shear stress produced by the experimental suspension divided by the shear stress produced by the control (unaggregated) suspension, a small correction being made for the effect on viscosity of the bacterial volume concentration.

Inhibition and reversal of haemagglutination by carbohydrate. Inhibition of haemagglutination was performed essentially as described above except $20 \mu \mathrm{l}$ of a stock solution of sugar was added before addition of the bacteria, to give a final concentration of $11 \mathrm{~mm}$ unless noted otherwise. For reversal of haemagglutination, the same quantity of carbohydrate was added with mixing at various times after addition of bacteria. Controls were treated similarly. All sugars were of the highest grade available (Sigma).

Reversal of haemagglutination by metal chelating agents. EDTA or EGTA (11 mM final concentration; Sigma) was added before, or at various times after, addition of bacteria.

Dependence on $\mathrm{pH}$. The effect of $\mathrm{pH}$ was tested in media containing $0.15 \mathrm{M}-\mathrm{NaCl}$, and $2 \mathrm{mM}-\mathrm{CaCl}_{2}$, buffered between $\mathrm{pH} 4.5$ and 9.0, the range over which the human erythrocyte is stable (Heard \& Seaman, 1960). An acetate buffer was used between $\mathrm{pH} 4.9$ and 6.2 and Tris (Sigma) from pH 7.2 to 9.0. The suspension $\mathrm{pH}$ was determined after the addition of cells.

\section{RESULTS}

Shear enhancement of haemagglutination. Figure 2 shows that before addition of bacteria, shearing of the erythrocyte suspension produced a constant value of shear stress $(R=1$, implying no aggregation). Addition of bacteria from a $42 \mathrm{~h}$ culture resulted in a rapid rise in shear stress which attained a steady value in about $10 \mathrm{~s}$. We have shown previously that the magnitude of this increase provides a quantitative index of the degree of aggregation present in the system (Brooks et al., 1974). In this case, the initial value of $R=2.0$ was maintained for the first $10 \mathrm{~min}$. A sample taken from the viscometer at this point and examined by light microscopy showed large aggregates of partially deformed erythrocytes. After about $10 \mathrm{~min}$, a secondary increase in $R$ was observed, which approached a second plateau of $R=3.9$ about $30 \mathrm{~min}$ after entering this second phase. Microscopic examination revealed massive aggregates of erythrocytes deformed into closely packed arrays.

This secondary increase in $R$ appeared to be induced by shearing the system. If bacteria were dispersed into a red cell suspension and incubated for $30 \mathrm{~min}$ in the viscometer in the absence of 


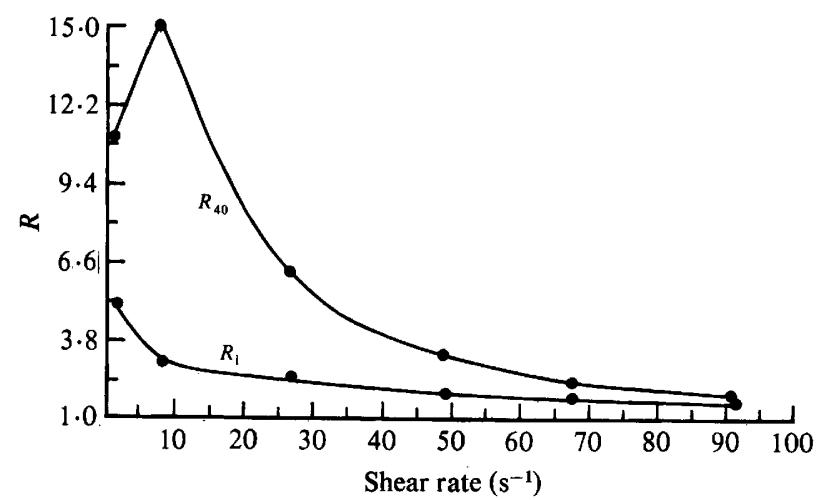

Fig. 3. Aggregation index observed approximately $1 \mathrm{~min}\left(R_{\mathrm{i}}\right)$ and $40 \mathrm{~min}\left(R_{40}\right)$ after the addition of $A$. salmonicida strain 438 to washed human red cells at the shear rates indicated and under the conditions described in the legend to Fig. 2.

shear, then shearing commenced, a steady value of $R=2.5$ was observed after 10 min, compared to $R=3.9$ in a sample sheared continuously for $40 \mathrm{~min}$ (Fig. 2). Continued shearing of the statically incubated suspension eventually increased $R$ to this level (not shown), but static incubation for several hours never produced this degree of aggregation without prolonged exposure to shear. Samples examined microscopically clearly showed stronger agglutination in the extensively sheared samples.

Because the general pattern of the shear stress-time records was similar under a variety of conditions, we found it convenient to qualitatively distinguish between the two phases of aggregation observed. We designated the initial phase of the reaction, from the time bacteria were added to the erythrocyte suspension through the first plateau in the shear stress-time curve, as Type I aggregation. Type I lasted about $10 \mathrm{~min}$ under the conditions in which the data in Fig. 2 was obtained. The secondary, shear-induced phase of the reaction, represented by the increase in $R$ and shear stress from about 10 to $\mathbf{4 0} \mathrm{min}$ after addition of bacteria, has been referred to as Type II aggregation.

Dependence on shear rate. Figure 3 shows the results obtained with $42 \mathrm{~h}$ cultures when the shear rate was varied. It is seen that between $91 \mathrm{~s}^{-1}$ and $1.2 \mathrm{~s}^{-1}$ the initial (Type I) $R$ value increased monotonically with decreasing shear rate. The $R$ value achieved after $40 \mathrm{~min}$ of shear also increased with decreasing shear rate down to a value of $11 \mathrm{~s}^{-1}$ but decreased as the shear rate was reduced further; the rate of increase of the trace in the Type II region behaved similarly (data not shown).

Effect of culture age on haemagglutination. The ability of $A$. salmonicida strain 438 to agglutinate human $\mathbf{A}(+)$ erythrocytes was strongly dependent upon culture age and the dependence differed for Type I and Type II agglutination. The results in Fig. 4 show that 18 to $24 \mathrm{~h}$ cultures produced little aggregation but that between 24 and $36 \mathrm{~h}$ the ability of the cells to cause both Type I (as judged by the initial value of $R$ ) and Type II aggregation (estimated from the value of $R 40 \mathrm{~min}$ after addition of bacteria) increased dramatically. Culture for longer periods resulted in a gradual decline in Type I aggregation, but Type II, after peaking at $42 \mathrm{~h}$, declined rapidly until beyond $54 \mathrm{~h}$ little shear-dependent agglutination was present.

Sugar inhibition and reversal. Figure 2 shows that addition of methyl- $\alpha$-D-mannoside $(\alpha \mathrm{MM})$ before addition of bacteria almost completely blocked haemagglutination, the trace only rising to a value of $R=1 \cdot 2$. When $\alpha \mathrm{MM}$ was added to Type I haemagglutination, i.e. within $5 \mathrm{~min}$ after bacterial addition, haemagglutination was reversed to the same extent that it could be inhibited, the trace falling to $R=1 \cdot 2$. However, when $\alpha \mathrm{MM}$ was added to shear-induced Type II aggregation, considerably less complete reversal was observed $(R=1 \cdot 7)$ and small aggregates of erythrocytes were visible microscopically. 


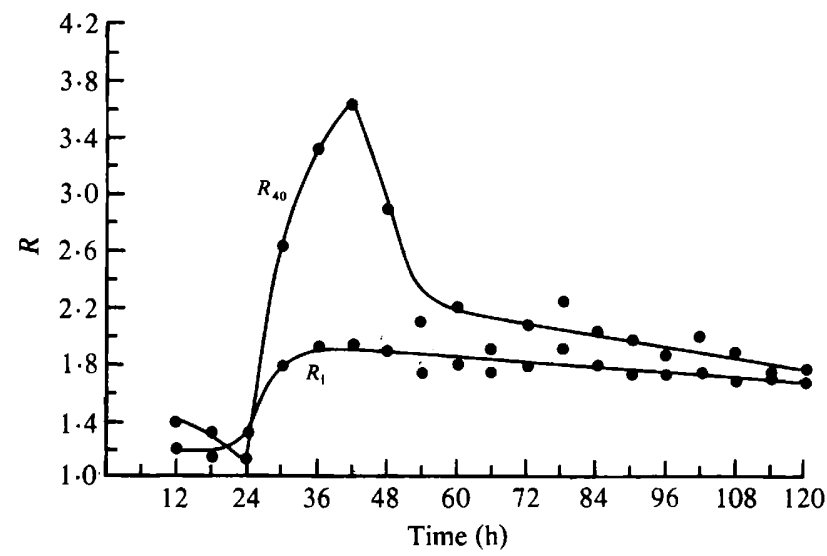

Fig. 4. Dependence of $R_{\mathrm{i}}$ and $R_{40}$ on the age of $A$. salmonicida strain 438 cultures. The conditions are as for Fig. 2.

Table 1. Inhibition and reversal by various monosaccharides of haemagglutination of human $A(+)$ erythrocyte suspensions induced by $A$. salmonicida 438

The haematocrit was $47 \%(\mathrm{v} / \mathrm{v})$, the bacterial concentration $2.6 \times 10^{1} \mathrm{ml}^{-1}$, the shear rate $49 \mathrm{~s}^{-1}$, the temperature $25.0{ }^{\circ} \mathrm{C}$ and the sugar concentration $11 \mathrm{mM}$ except for yeast mannan which was $0 \cdot 18 \%$ $(\mathrm{w} / \mathrm{v}) . R_{\mathrm{i}}$ and $R_{40}$ are defined in Fig. 3 .

\begin{tabular}{|c|c|c|c|c|c|}
\hline Sugar & $\frac{\mathrm{C}}{\boldsymbol{R}_{\mathrm{i}}}$ & $\overbrace{R_{40}}^{\text {trol }}$ & $\begin{array}{c}\text { Inhibition } \\
R_{\mathrm{i}}\end{array}$ & $\begin{array}{c}\text { Type I reversal } \\
R_{\min }\end{array}$ & $\begin{array}{c}\text { Type II reversal } \\
R_{\min }\end{array}$ \\
\hline None & $1 \cdot 6$ & 3.0 & & & \\
\hline$\alpha \mathrm{MM}$ & & & $1 \cdot 1$ & $1 \cdot 1$ & $1 \cdot 5$ \\
\hline L-fucose & & & $1 \cdot 2$ & $1 \cdot 2$ & $1 \cdot 4$ \\
\hline D-fucose & & & $1 \cdot 7$ & $1 \cdot 7$ & $3 \cdot 0$ \\
\hline D-galactose & & & $1 \cdot 6$ & 1.6 & $3 \cdot 0$ \\
\hline D-mannose & & & $1 \cdot 1$ & $1 \cdot 2$ & $1 \cdot 3$ \\
\hline D-mannoheptulose & & & $1 \cdot 1$ & $1 \cdot 2$ & $1 \cdot 6$ \\
\hline D-mannose-6-phosphate & & & $1 \cdot 4$ & $1 \cdot 5$ & 1.9 \\
\hline D-glucose & & & $1 \cdot 6$ & $1 \cdot 6$ & $3 \cdot 0$ \\
\hline D-altrose & & & $1 \cdot 4$ & $1 \cdot 6$ & $2 \cdot 2$ \\
\hline Yeast mannan & & & $1 \cdot 3$ & $1 \cdot 3$ & $2 \cdot 0$ \\
\hline
\end{tabular}

The specificity of the haemagglutination reaction was examined by determining the degree of inhibition and reversal produced by a variety of sugars, with the results shown in Table 1 . Inhibition was assayed by adding each of the sugars tested before bacteria were added, then calculating the initial $R$ value, $R_{\mathrm{i}}$, about $1 \mathrm{~min}$ after addition of bacteria. Type I and Type II reversal were determined by adding the same concentration of sugar $6 \mathrm{~min}$ (Type I) and $40 \mathrm{~min}$ (Type II) after bacteria were introduced, and recording the minimum $R$ value obtained subsequently, $R_{\min }$. The extent of reversal can be assessed by comparing these values respectively with the initial $R$ value, $R_{\mathrm{i}}$, and that found after $40 \mathrm{~min}, R_{40}$, in the absence of added sugar.

Dependence on $p H$. Figure 5 shows the dependence of Type I (as reflected by the value of $R_{\mathrm{i}}$ ) and Type II aggregation (indicated by $R_{40}$ ) on the $\mathrm{pH}$ of the suspending medium over the range 4.9 to $9 \cdot 1$. It is seen that the degree of Type I aggregation was constant above pH 6.2 and was present at a reduced but measurable level between $\mathrm{pH} 4.9$ and 6.2. Type II agglutination was weakly present at $\mathrm{pH} 4.9$ but increased strongly to a peak around $\mathrm{pH} 7$, decreasing rapidly above about $\mathrm{pH} 7.5$ until the shear component disappeared completely at $\mathrm{pH} 9$. 


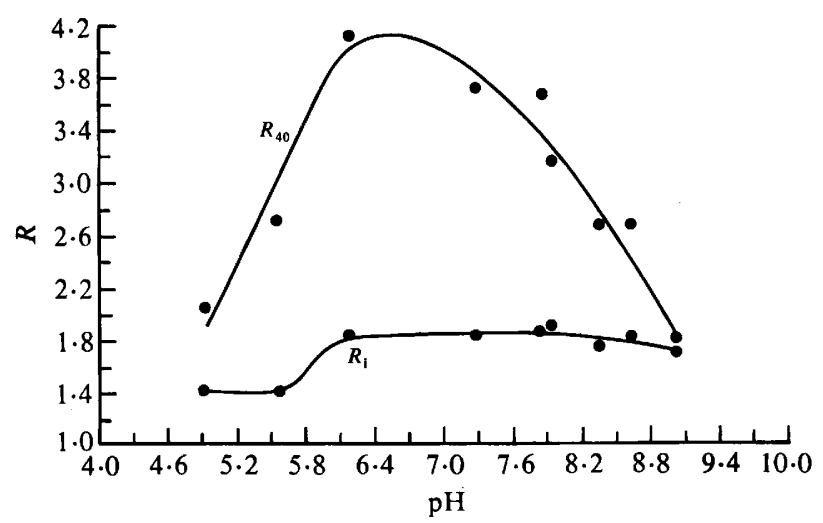

Fig. 5. Dependence of $R_{\mathrm{i}}$ and $R_{40}$ on the $\mathrm{pH}$ of the suspension. The conditions are as for Fig. 2 except for the differences in suspending media described in the text.

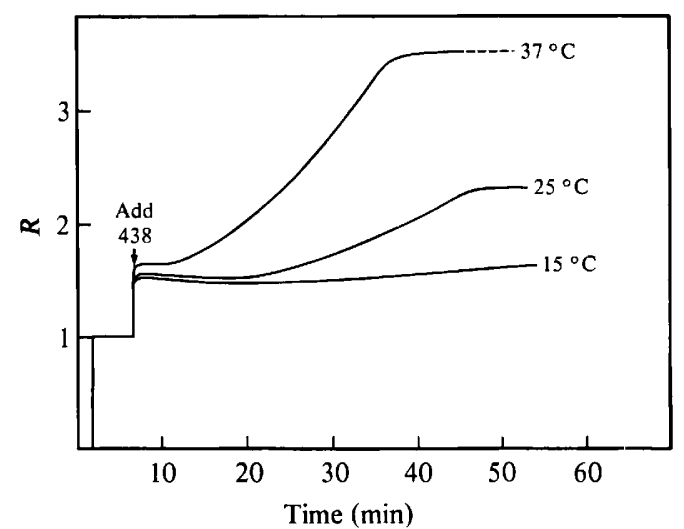

Fig. 6. Aggregation index observed as a function of time at the three temperatures indicated. The conditions are otherwise as for Fig. 2.

Dependence on temperature. The sensitivity of Type I and Type II aggregation to temperature is illustrated in Fig. 6. It is seen that the Type I reaction was virtually independent of temperature but that Type II aggregation increased strongly with increasing temperature, being nearly absent at $15^{\circ} \mathrm{C}$ but very evident at $37^{\circ} \mathrm{C}$.

Dependence on bacterial concentration. Figure 7 illustrates the dependence of $R_{\mathrm{i}}$ and $R_{40}$ on the number of bacteria present, the latter generally representing the maximum value attained. The bacterial concentration was expressed as the number of micro-organisms added per erythrocyte, the ratio being varied by adding different numbers of bacteria while maintaining a constant haematocrit. Both $R_{\mathrm{i}}$ and $R_{40}$ showed the same dependence on bacterial concentration; each displayed simple saturable behaviour with saturation appearing above a ratio of about 40 bacteria added per red cell.

Dependence on divalent cations. Figure 2 illustrates a specific example of the general result found, namely that either EDTA or EGTA was capable of completely reversing the trace to $R=1.0$ at any stage of the reaction. Hence, haemagglutination induced by $A$. salmonicida 438 has an absolute requirement for $\mathrm{Ca}^{2+}$. The concentration dependence and ability of other multivalent cations to substitute are both complex problems, however, and have been dealt with in a separate publication. 


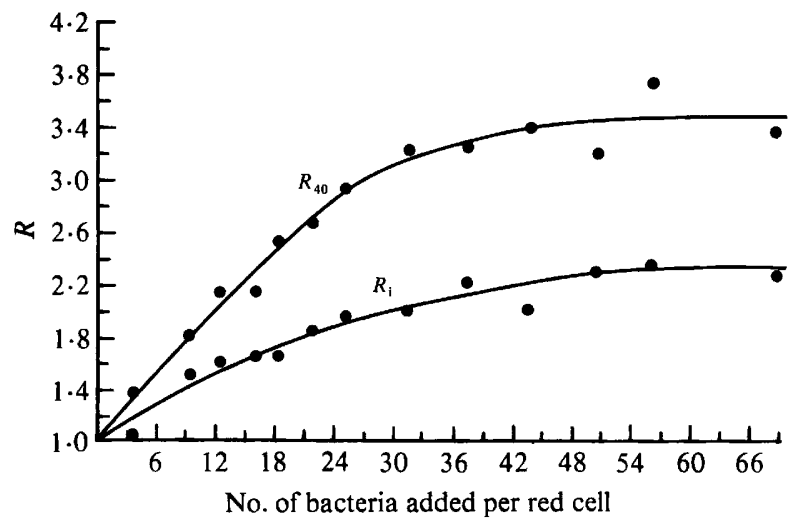

Fig. 7. Dependence of $R_{\mathrm{i}}$ and $R_{40}$ on the ratio of the number of bacteria added to the number of red cells present in the suspension. Red cell final concentration was $4.6 \times 10^{9} \mathrm{ml}^{-1}$; other conditions are as for Fig. 2.

\section{DISCUSSION}

The experiments described above are apparently the first to study in detail the effects of known shear stresses on bacterial adhesion to eucaryotic cells, although considerable attention has been paid to this parameter in adhesion to non-biological surfaces (Fowler \& McKay, 1980; Bryers \& Characklis, 1982). The results demonstrate clearly that certain aspects of haemagglutination induced by adherent bacteria are progressively enhanced under shear, a result strongly paralleling that obtained when con A haemagglutination was studied by the same techniques (Greig \& Brooks, 1979). Most erythroctyte aggregation reactions do not respond to shear in this way, however (Brooks et al., 1980). The usual result obtained when aggregation is studied in a viscometer is that a constant level of shear stresses is reached upon adding an aggregating agent such as fibrinogen or dextran, so that $R$ remains constant with time of shearing. This behaviour corresponds exactly to what we have termed Type I aggregation in the present work. The secondary, shear-induced increase in $R$ has thus far only been reported for haemagglutination induced by tetravalent con $A$ and does not occur in aggregation induced by whole antisera raised against blood group antigens or by divalent con A (R. G. Greig \& D. E. Brooks, unpublished).

The source of the increase in shear stress observed upon induction of aggregation is believed to be the increased energy dissipation associated with the breaking of intercellular attachments (D. E. Brooks \& R. G. Greig, unpublished). This dissipation results both from breaking of bonds between the bacterial and erythrocyte membranes and from the elastic deformation of the red cells which occurs during this process. Because of the complex nature of the events involved it is not possible at present to interpret the shear stresses observed in terms of numerical bond strengths. We therefore take the relative shear stress, $R$, to be a quantitative index of the rate of energy dissipation associated with the continual separation of adherent cells by the shear field.

The initial phase of erythrocyte aggregation induced by strain 438 (Type I) exhibits characteristics very similar to those determined via observation of haemagglutination on a glass slide for this system (Trust et al., 1980). A similar parallel in results between viscometric and microscopic assessment of aggregation was found in studies of dextran-red cell interactions (Brooks et al., 1974). Hence, the initial $R$ values measured quantify the effects of bacterial adhesion to cells in the sense it is usually studied. For instance, the varying abilities of the sugars listed in Table 1 to inhibit aggregation in the viscometer are in agreement with slide haemagglutination studies reported previously (Trust $e t$ al., 1980). The abilities of the sugars to reverse Type I aggregation likewise parallel the earlier results. We find, however, that neither inhibition nor Type I reversal is complete and that a low level of residual aggregation insensitive to high concentrations of saccharides is present (indicated by the values of $R>1.0$ in the presence of 11 mM-sugar). 
The characteristic of the shear-induced phase of the reaction (Type II) differ in a number of ways from those of Type I aggregation, suggesting a difference in the underlying biochemical mechanisms involved. The mechanisms responsible for the Type II reaction are not known, but a plausible model has been presented for the con A-erythrocyte system (R. G. Greig \& D. E. Brooks, unpublished) which invokes the slow, shear-assisted rearrangement (convection) of integral membrane glycoprotein receptors as a necessary component of the reaction. The rearrangement could allow for progressively more and/or stronger associations between lectin (or adhesin)-binding sites and membrane oligosaccharides. These stronger associations, in turn, could result in the shear-dependent increases in $R$ and the refractoriness to reversal by sugars we observe.

None of the evidence accumulated to date in the present system is inconsistent with the above model. It is possible, on the other hand, that shearing could have a direct effect on the organization of bacterial membrane structures involved in adhesion that would produce the observed behaviour.

In almost every aspect examined in this study, Type I aggregation differed from the secondary, shear-dependent phase, implying that distinct biochemical mechanisms are responsible for the two. In terms of shear-rate dependence, dependence on culture age, reversibility by dissolved sugars and the effects of $\mathrm{pH}$ and temperature, the two classes of aggregation behaved very differently. The initial $R$ value, the parameter taken to characterize Type I aggregation, increases continuously with decreasing shear rate. This is probably partly due to the relatively greater fraction of energy dissipation associated with aggregate dissociation as the shear rate is decreased. Broadly speaking, energy is dissipated both in the disruption of intercellular attachments and in the subsequent flow of the suspension. As the shear rate is decreased, proportionately less energy is required to make the system flow (once disaggregated). The energy dissipation associated with breaking intercellular attachments should be more independent of shear rate, however, so it becomes a progressively larger fraction of the total as the shear rate is lowered, causing at least in part the increase in $R_{\mathrm{i}}$ observed. The second possible cause of the behaviour illustrated in Fig. 3 derives from the kinetics of bond formation. If attachments are incompletely made during the time two cells pass each other in the shear field, reduction in shear rate would increase the number and/or strength of attachments made, which would also produce an effect like that observed.

The peak observed in the plot of $R_{40}$ versus shear rate implies a more complex dependence of Type II aggregation on shear. Apparently at low shear rates there is insufficient shear stress acting on the system to induce the maximal Type II reaction. At sufficiently high shear rates, on the other hand, the effects discussed above come into play and $R$ decreases. At some intermediate shear rate, therefore, a maximum in the $R$-shear rate curve could occur, as observed.

The dependences of Type I and Type II aggregation on culture age also are markedly different. Assuming the Type I reaction represents the appearance or unmasking of significant numbers of bonding molecules on the bacterial surface, it is clear that a considerable amount of growth (about $36 \mathrm{~h}$ ) is required before the individual cells maximize their ability to adhere to erythrocyte surfaces. The ability to produce the shear-induced reaction also appears during this period, but is maximized somewhat later $(42 \mathrm{~h})$ than the Type I reaction, following which it falls steeply. We have no information on the nature of the surface structures responsible for the above behaviour. Based on our work with con $A$, however, a possible explanation would be the progressive appearance up to $42 \mathrm{~h}$, of multivalent lectin-like molecules on the bacterial surface. This suggestion is based on the observation (R. G. Greig \& D. E. Brooks, unpublished) that divalent con A does not produce Type II aggregation while tetravalent con A does. This is only one of a number of possible explanations, however. The decrease in $R_{40}$ in cultures older than $42 \mathrm{~h}$ could be due simply to the disappearance or masking of the involved surface structures.

Further evidence that Type I and Type II are distinct reactions comes from the $\mathrm{pH}$ and temperature dependence (Figs 5 and 6). Type I aggregation is nearly independent of temperature between 15 and $37^{\circ} \mathrm{C}$ and appears to depend in some way on a chemical species with an apparent $\mathrm{p} K_{\mathrm{a}}$ of about $5 \cdot 9$, the reaction remaining constant above this region. The Type 
II effect peaks between pH 6 and 7 and falls off sharply on both sides. It is also strongly enhanced as the temperature increases over the range studied. Hence, the shear-induced phase is more complex, perhaps reflecting a more complex mechanism than simple binding and agglutination.

There are certain features of Type I and Type II aggregation which do vary in parallel under some manipulations, however. In particular, the dependence of $R_{\mathrm{i}}$ and $R_{40}$ on the ratio of the numbers of bacteria to erythrocytes is very similar, both curves showing half saturation values of about 16 bacteria added per red cell (Fig. 7). Also, although the various sugars listed in Table 1 reverse Types I and II to different extents, the relative effectiveness of the sugars varies in parallel for the two phases of the reaction. That is, those sugars which are the most effective in reversing Type I aggregation produced the greatest reversal of Type II. Finally, neither Type I nor Type II aggregation appear in the presence of EDTA or EGTA, suggesting that both reactions are $\mathrm{Ca}^{2+}$ dependent.

The basic observation that in some circumstances shear forces can enhance the strength of bacterial adhesion could be of fundamental importance in our understanding of the colonization of mammalian cell surfaces in the vasculature and in the respiratory, gastrointestinal and urinary tracts. In such environments the ability of shear stresses to induce adhesion which is progressively more refractory to reversal by saccharide inhibitors may also have clinical significance. Our findings suggest that 'receptor megatherapy' with simple sugars, which has been proposed as a procedure whereby bacterial attachment in vivo could either be inhibited or reversed (Keusch, 1979) might not be entirely successful in the presence of shear.

We thank Ms Mandy Hoskins for her meticulous technical assistance and the B. C. Health Care Research Foundation for their support of portions of this work.

\section{REFERENCES}

Brooks, D. E. \& TRust, T. J. (1980). An improved technique for the study of bacterial adhesion to surfaces. In Microbrial Adhesion to Surfaces, pp. 513515. Edited by R. C. W. Berkeley, J. M. Lynch, V. Molling, P. R. Butter \& B. Vincent. Chichester: Ellis Horwood.

Brooks, D. E., Goodwin, J. W. \& Seaman, G. V. F. (1974). Rheology of erythrocyte suspensions : electrostatic factors in the dextran-mediated aggregation of erythrocytes. Biorheology 11, 69-77.

Brooks, D. E., Greig, R. G. \& JanzeN, J. (1980). Mechanisms of erythrocyte aggregation. In Erythrocyte Mechanics and Blood Flow, pp. 119-140. Edited by G. Cokelet, H. Meiselman \& D. E. Brooks. New York: Alan R. Liss.

Bryers, J. D. \& Characklis, W. G. (1982). Processes governing primary biofilm formation. Biotechnology and Bioengineering 24, 2451-2476.

Duguid, J. P. \& OLD, D. C. (1980). Adhesive properties of Enterobacteriaceae. In Receptors and Recognition, Series B, vol. 6, pp. 185-217. Edited by E. H. Beachey. London: Chapman \& Hall.

Fowler, H. W. \& McKay, A. J. (1980). The measurement of microbial adhesion. In Microbial Adhesion to Surfaces, pp. 143-161. Edited by
R. C. W. Berkeley, J. M. Lynch, V. Molling, P. R. Rutter \& B. Vincent. Chichester: Ellis Horwood.

GreIG, R. G. \& Brooks, D. E. (1979). Shear-induced concanavalin A agglutination of human erythrocytes. Nature, London 282, 738-739.

GrEIG, R. G. \& BRooks, D. E. (1981). Enhanced concanavalin A agglutination of trypsinised erythrocytes is due to a specific class of aggregation. Biochemica et biophysica acta 641, 410-415.

Heard, D. H. \& Seaman, G. V. F. (1960). The influences of $\mathrm{pH}$ and ionic strength on the electrokinetic ability of the human erythrocyte membrane. Journal of General Physiology 43, 635-654.

JONES, G. W. (1977). The attachment of bacteria to the surfaces of animal cells. In Receptors and Recognition, Series B, vol. 3, pp. 139-176. Edited by J. L. Reissig. London: Chapman \& Hall.

KeUSCH, G. T. (1979). Specific membrane receptors: pathogenic and therapeutic implications in infectious disease. Reviews on Infectious Diseases 1, 517529.

Trust, T. J., Courtice, L. D. \& Atkinson, H. M. (1980). Hemagglutination properties of Aeromonas. In Fish Diseases, pp. 218-223. Edited by W. Ahne. Berlin: Springer-Verlag. 